\title{
Two-stage PCR assay for detection of human brucellosis in endemic areas
}

\author{
Ibrahim Hassan Kamal ${ }^{1,2^{*}}$, Basim Al Gashgari ${ }^{1}$, Said Salama Moselhy ${ }^{1,2}$, Taha Abdullah Kumosani ${ }^{1,3}$ \\ and Khalid Omar Abulnaja ${ }^{1}$
}

\begin{abstract}
Background: Brucellosis is a common zoonosis that can cause a severe febrile illness in humans. It constitutes a persistent health problem in many developing countries around the world. It is one of the most frequently reported diseases in Saudi Arabia and incidence is particularly high in the Central region, and around the city of Riyadh. The aim of this study was to evaluate a two-stage PCR assay for detection of human brucellosis particularly in endemic areas.
\end{abstract}

Methods: A total of 101 serum samples were collected from patients with acute febrile illness (AFI) of unknown cause from two different locations in the Western region of Saudi Arabia. The first location (Northern) is characterized by a nomadic rural population while the second (Central) is a modern urban city. All samples were subjected to DNA extraction and Brucella genus-specific PCR amplification using B4/B5 primers of the bcsp31 gene. Positive B4/B5 samples were subjected to multiplex species-specific Brucella PCR amplification.

Results: In the Northern location, $81.9 \%$ of the AFI samples were confirmed Brucella positive, while all the samples collected from the Central region proved to be Brucella negative. Samples positive for Brucella were subjected to multiplex species-specific Brucella amplification. B. abortus was detected in 10\% and B. melitensis in $8 \%$ of the samples, while the majority (82\%) of samples showed both B. abortus and B. melitensis. As expected, B. suis was not detected in any of the samples.

Conclusions: This study concluded that a two-stage PCR assay could be useful as a rapid diagnostic tool to allow the consideration of brucellosis as a possible cause of AFI, particularly in non-urban locations. It also recommends the collection of epidemiological data for such patients to obtain further information that may help in rapid diagnosis.

\section{Background}

The etiology and incidence of acute febrile illness (AFI) represents a major public health problem because clinical diagnosis is usually unreliable, and diagnostic tests are often not available in disease endemic areas [1]. Surveillance based on symptoms alone frequently results in classification errors, because febrile illnesses resulting from different pathogens may be clinically indistinguishable. Ideally a good surveillance system should be supported by modern molecular diagnostic tests and be

\footnotetext{
* Correspondence: imbc57@yahoo.com

'Biochemistry Department, Faculty of Science, King Abdulaziz University, Jeddah, Saudi Arabia

${ }^{2}$ Biochemistry Department, Faculty of Science, Ain Shams University, Cairo, Egypt

Full list of author information is available at the end of the article
}

sensitive and specific enough to accurately reflect the causes of febrile illnesses in a population. Brucellosis is a severe acute febrile disease caused by Gram-negative bacteria of the genus Brucella. It is the cause of a wide range of significant veterinary and public health problems, and economic loss [2]. The eradication of human brucellosis is difficult and the disease has a serious medical impact worldwide [3]. The acute febrile clinical symptoms of brucellosis always overlap with those of other etiological pathogens, and this may lead to misdiagnosis as well as improper antibiotic treatment regimes.

Human brucellosis is one of the most frequently reported diseases in Saudi Arabia, particularly in the Central region and around the city of Riyadh [4-10]. Since brucellosis is a zoonotic disease, it is transmitted from animals to humans by direct contact with infected

\section{Ciomed Central}


animals or consumption of raw animal products such as unpasteurized milk or cheese. Direct contact with infected animals, their secretions or their carcasses can lead to infection through inhalation or accidental skin and mucous membrane penetration [11,12]. In Saudi Arabia, brucellosis has been recognized as a major health problem, and measures to control the disease were implemented as early as 1983 [13].

Four species of the genus Brucella are pathogenic for humans, namely B. melitensis (from sheep and goats), $B$. abortus (from cattle and other bovidae), B. suis (from pigs), and B. canis (from dogs) [14]. Queipo-Ortuno and coworkers [15] found $100 \%$ sensitivity and $98.3 \%$ specificity using the B4/B5 primer pair amplifying a $223 \mathrm{bp}$ fragment of the $b c s p 31$ gene, compared with $70 \%$ sensitivity for diagnosis by blood culture. PCR identification of Brucella strains at the species or biovar level has been described by Redkar et al. [16], who developed a realtime PCR assay for the detection of $B$. abortus, $B$. melitensis, and $B$. suis biovar 1 . These PCR assays target the specific integration of IS711 elements within the genome of the respective Brucella species or biovar.

In most developing countries, especially in non-urban areas, real-time PCR facilities are not available as a diagnostic tool for human brucellosis. Most diagnostic laboratories still rely on routine laboratory tests such as bacterial culturing and serological tests, even though thermal cyclers may be available. In this study, we took the initiative to evaluate a two-stage PCR assay as a rapid sensitive diagnostic tool for diagnosis of human brucellosis, to highlight the need to consider brucellosis in the differential diagnosis of AFI, particularly in nonurban areas where patients are known to have a risk of exposure and Brucella incidence is expected to be high.

Two different locations in the Western region of Saudi Arabia were selected to test the two-stage PCR strategy. The Northern location is characterized by a nomadic, mostly Bedouin population who consume unpasteurized dairy products and ingest fresh camel, goat and sheep milk. The Central location was in a modern urban city where the Bedouin population is low and the chances of using unpasteurized dairy products or direct exposure to animals are limited. These two locations were selected to test the likelihood of Brucella infection being a major cause of AFI especially in rural locations, where the lifestyle of the population allows contact with Brucellainfected animals.

\section{Methods}

\section{Subjects}

A total of 101 serum samples were collected from the two selected locations in the Western region of Saudi Arabia. In the Northern region, samples were from the Armed Forces hospital of Tabuk during the period June
2009 to January 2011, and in the Central region samples were collected at King Abdulaziz Hospital of Jeddah during the period November 2009 to November 2011. Serum was obtained from patients aged 1 year or older suffering from unknown fever of more than 2 days' duration who sought medical help in hospital. AFI was defined as a body temperature $\geq 38^{\circ} \mathrm{C}$ at the time of collection, or fever of more than 2 days, and no other identified cause of fever such as diarrhea, hepatitis or any respiratory tract infections. Control serum samples were collected from 20 healthy volunteers from the same locations. No family history or any occupational exposure to Brucella infection was recorded for the healthy controls. All participants meeting inclusion criteria were asked to participate in this study. Informed written consent was obtained from adult participants and parents of minors.

All samples were subjected to DNA extraction as previously described [17], with minor modifications as follows: $1 \%$ of sodium dodecyl sulfate (SDS) and $10 \mathrm{mg} / \mathrm{ml}$ of proteinase $\mathrm{K}$ were added to $300 \mathrm{ul}$ of serum and incubated for $2 \mathrm{~h}$ at $37^{\circ} \mathrm{C}$. Proteinase $\mathrm{K}$ in the digest was inactivated by heating at $90-95^{\circ} \mathrm{C}$ for $10-15 \mathrm{~min}$. After phenol-chloroform-isoamyl alcohol extraction and ethanol precipitation, DNA was dissolved in 50 ul of nuclease-free water.

\section{Brucella genus-specific DNA amplification}

To diagnose the Brucella positive samples, the first PCR amplification was carried out using primers designed to target a $223 \mathrm{bp}$ fragment of the bcsp31 gene. This sequence encodes an immunogenic membrane protein of a $31 \mathrm{kDa}$ antigen of $B$. abortus and is conserved in all Brucella biovars [18]. A pair of 21-nucleotide primers, B4 (5' TGG CTC GGT TGC CAA TAT CAA $\left.3^{\prime}\right)$ and B5 (5' CGC GCT TGC CTT TCA GGT CTG 3'), were obtained from Bioline, Inc., (Taunton, MA, USA), as described by Baily et al. [19]. PCR was performed in a $25 \mathrm{ul}$ mixture containing template DNA; PCR buffer $(10 \mathrm{mM}$ Tris $\mathrm{HCl}$ [pH 8.4], $50 \mathrm{mM} \mathrm{KCl}, 1.5 \mathrm{mM} \mathrm{MgCl}$ ); 10 pmol of each primer; $200 \mathrm{uM}$ (each) of dATP, dCTP, dTTP and dGTP (Bioline, Inc.), and $1.25 \mathrm{U}$ of Taq polymerase (Qiagen, Chatsworth, NJ, USA). The cycle consisted of a preheating step at $95^{\circ} \mathrm{C}$ for $5 \mathrm{~min}$ followed by 35 cycles of $90^{\circ} \mathrm{C}$ for $1 \mathrm{~min}, 60^{\circ} \mathrm{C}$ for $30 \mathrm{~s}$, and $72^{\circ} \mathrm{C}$ for $1 \mathrm{~min}$ with a final incubation at $72^{\circ} \mathrm{C}$ for $10 \mathrm{~min}$. A positive control based on DNA from a $B$. abortus reference strain was included in all tests, as well as a negative control containing all of the components of the reaction mixture except DNA. 20\% of each PCR product was visualized on a $1 \%$ agarose gel stained with $2 \mathrm{ug} / \mathrm{ml}$ of ethidium bromide.

\section{Multiplex species-specific Brucella DNA amplification} All samples positive using the B4/B5 primers were subjected to multiplex PCR to determine which Brucella 
species might be causing the infection. Species-specific DNA segments of B. abortus, B. melitensis and B. suis were targeted for amplification using specific primers derived from the IS711 element [20]. The forward primer (5' CAT GCG CTA TGT CTG GTT AC 3') spans 803 to 823 nt of $I S 711$ and generates a 113 bp PCR product with $B$. abortus reverse primer $\left(5^{\prime}\right.$ GGC TTT TCT ATC ACG GTA TTC 3'), 252 bp PCR product with B. melitensis reverse primer ( $5^{\prime}$ AGT GTT TCG GCT CAG AAT AAT C $3^{\prime}$ ), and 170 bp product with B. suis reverse primer $\left(5^{\prime}\right.$ ACC GGA ACA TGC AAA TGA C $\left.3^{\prime}\right)$. Amplification conditions were the same as for the first PCR, except for the use of an annealing temperature of $58^{\circ} \mathrm{C}$. Positive and negative PCR controls were used in all tests. B. suis primers were used as an internal negative PCR control. B. suis is pathogenic to pigs, which are not found in Saudi Arabia. PCR products were visualized on a $1 \%$ agarose gel as previously described.

\section{Results}

A total of 101 AFI patients were enrolled in this study in the Western region of Saudi Arabia; 61 and 40 from the Northern and Central locations, respectively. Their characteristics are presented in Table 1. Forty-four samples (72\%) from the Northern location were serologically positive for Brucella with varying titers (data not shown). All samples were subjected to Brucella genus amplification using B4/B5 primers that amplify a conserved region in all Brucella species to detect the presence of Brucella DNA as one of the possible causes of the AFI.

Agarose gel electrophoresis of the B4/B5 conventional PCR amplification gave a product size of $223 \mathrm{bp}$, indicating the presence of Brucella genus in these patients. The PCR control of the Brucella reference strain amplified a product of a similar size. No amplification was detected in the negative PCR control, or in the negative control subjects. Conventional PCR confirmed that 50 samples (81.9\%) were diagnosed as Brucella positive out of the 61 samples collected from the Northern location, leaving $11(18 \%)$ patients whose AFI was of non-Brucella origin. No human brucellosis was detected in the 40 samples collected from the Central location.

DNA from the 50 Brucella positive patients were subjected to the species-specific multiplex PCR. Multiplex
PCR electrophoresis results are shown in Figure 1, which illustrates the presence of 113 bp and 252 bp bands specific for B. abortus and B. melitensis, respectively. Among the 50 samples, $B$. abortus alone was evident in five samples (10\%) and B. melitensis alone in four samples (8\%), while the rest of the samples (82\%) showed products of both B. abortus and B. melitensis (Table 2). The B. suis amplification product (170 bp) was not detected in any of the samples. These results confirmed the specificity and sensitivity of these primers for the targeted region in Brucella DNA.

\section{Discussion}

AFI still represents a common clinical syndrome among patients seeking hospital care. Brucella is one of a number of pathogens causing febrile illness, and is a serious public health problem in many developing countries, including Saudi Arabia; where many people, by their traditional lifestyle, consume raw milk or have close animal contact [21]. The true human brucellosis incidence has been estimated to be between 10 and 25 times higher than the number of annual reported cases [22].

Diagnosis of human brucellosis in Saudi Arabia currently depends mainly on culture [23] and serological tests [24]. Brucella is a highly virulent bacterium and may constitute exposure hazards for laboratory personnel. Furthermore, its culture is time consuming and the isolation rate is low, which may cause critical diagnostic delays [25]. At the early stage of infection, the sensitivity of serologic tests is low and false-negative or only weak-positive reactions may occur [26]. Because of limitations of culture techniques and serological tests, various molecular methods, particularly PCR, have been developed for rapid identification of organisms in clinical samples. The PCR technique has proved to be a very useful, simple, quick, sensitive, specific and relatively inexpensive technique that merits its adoption in clinical laboratories. Several articles have been published dealing with various PCR-based methods for Brucella detection.

In this study, a two-stage PCR assay was tested. The genus-specific PCR assay, which targets the $223 \mathrm{bp}$ sequence of the gene encoding a $31 \mathrm{kDa}$ Brucella abortus antigen [19], and the multiplex amplification for the identification of Brucella to the species level called

Table 1 Characteristic features of patients with AFI

\begin{tabular}{lcr}
\hline Characteristic & \multicolumn{2}{c}{ Values } \\
\cline { 2 - 3 } & \multicolumn{2}{c}{ Locality at Western region } \\
\hline No. of AFI samples collected & 61 & Northern \\
No. of Brucella seropositive samples (data not shown) & $44 / 61$ & 40 \\
No. of samples subjected to conventional PCR (B4/B5) amplification & $61 / 61$ & $00 / 40$ \\
No. of samples subjected to species-specific PCR & $50 / 61$ & $40 / 40$ \\
\hline
\end{tabular}




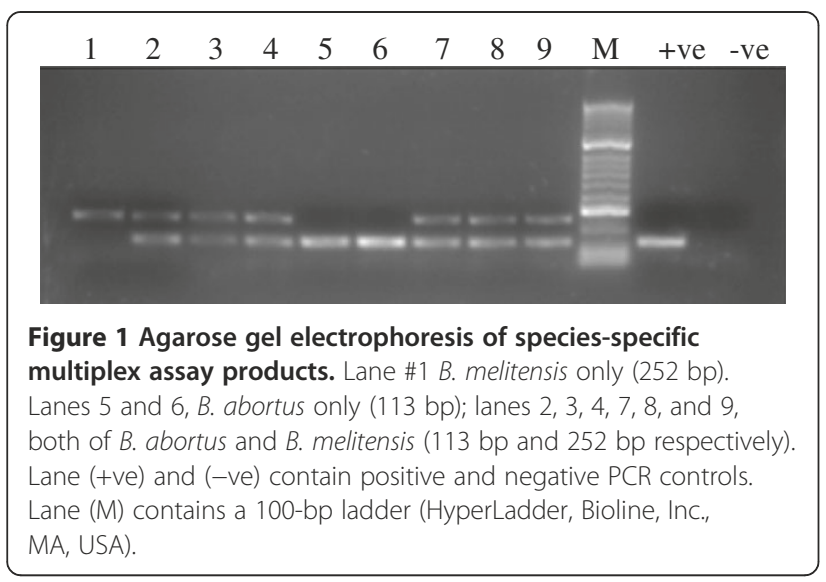

AMOS PCR for B. abortus, B. melitensis, B. ovis and B. suis [20], were carried out on 110 Saudi Arabian serum samples from patients with AFI. Brucella genus-specific B4/B5 primers detected the presence of the predicted 223 bp fragment in $81.9 \%$ of serum samples collected from the Northern location, but did not detect any Brucella cases out of the 40 samples collected from Central location. These results indicated that using serum as a clinical sample and the two PCR sequential assays provided a sensitive assay for diagnosis of human brucellosis. Similar results were reported by Elfaki and coworkers [27], who reported the presence of the same PCR fragment (223 bp) in 96\% of the sera samples from 25 patients with symptoms of brucellosis from two reference hospitals in Central Saudi Arabia.

The Brucella species-specific multiplex PCR classified the Brucella genus positive samples into single B. abortus or B. melitensis or double infection (both B. abortus and $B$. melitensis), which represented the majority of cases $(81 \%)$. B. suis primers failed, as predicted, since swine are not domestic in Saudi Arabia. Similar results were previously recorded in Saudi Arabia [27].

Our results support other studies [27,28], which recommended the use of PCR as the diagnostic tool of choice for human brucellosis. Since the samples in this study were collected randomly with very limited case histories, we could not classify the brucellosis as acute, chronic or relapsing cases.

The existence of the double product may be attributed to active double infection or to the coexistence of free DNA of one or both species in the tested samples. The free DNA in serum may reflect the degradation of Brucella cells during the bacteremic phase of infection [27]. Double infection may be attributed to keeping livestock of different species. The incidence of animal brucellosis in the Saudi Arabia Makkah region was previously found to be $0.8 \%$ in goats, $0.5 \%$ in sheep, $2.8 \%$ in camels and $3.6 \%$ in cows [29]. Ten years later in the Asir region, it had risen to $18.2 \%$ in goats, $12.3 \%$ in sheep, $22.6 \%$ in camels and $15.5 \%$ in cows [30].

Our results succeeded in highlighting the differences between the two selected locations in this study, where the non-urban area (Northern location) showed a high incidence of human brucellosis among the AFI patients, which could be due to probable exposure to infected dairy products or direct contact with infected animals common in the nomadic Bedouin population lifestyle in such rural locations. On the other hand, our assay failed to detect any brucellosis in samples collected from the urban city (Central location), where the Bedouin population is limited and exposure risk is low.

As mentioned by Dean and co-authors [31], health service inadequacies are compounded by socioeconomic factors, with brucellosis affecting poor, marginalized communities who often do not have the means to seek treatment. A study conducted in rural Tanzania revealed that 1 in 5 patients did not present to a health center for assessment until more than 1 year after the onset of illness. As a result of false-negative results, $44.8 \%$ brucellosis cases were not diagnosed at the hospitals on their first visit. These cases were treated for other diseases such as malaria, which is much more common in the rural area than brucellosis, and the brucellosis remained untreated [32]. Given the high proportion of brucellosis cases with fever, brucellosis should be considered as a differential diagnosis for fevers of unknown origin. Many patients from non-urban areas do not report to healthcare facilities.

\section{Conclusions}

This study concluded that a two-stage PCR assay could be useful as a rapid diagnostic tool to highlight the need to consider brucellosis as a possible cause of AFI, particularly in non-urban locations.

The two-stage PCR assay minimizes exposure risks to laboratory personnel for this virulent bacterium and also shortens the diagnostic time. It may also be considered as an epidemiological tool for disease confirmation,

Table 2 Brucella DNA amplification using B4/B5 and species-specific multiplex PCR

\begin{tabular}{|c|c|c|c|c|c|}
\hline \multirow{3}{*}{$\begin{array}{l}\text { (AFI) Samples locality } \\
\text { (Western region) } \\
\text { (number) }\end{array}$} & \multicolumn{2}{|c|}{ Brucella genus B4/B5 conventional PCR } & \multicolumn{3}{|c|}{ Brucella species-specific multiplex } \\
\hline & -ve amplification & +ve amplification & Double product & Single product & Single product \\
\hline & Non- Brucella patients & Brucella patients & B. abortus \& B. melitensis & B. abortus & B. melitensis \\
\hline (Northern region) (61) & 11 & 50 & $41(82 \%)$ & $5(10 \%)$ & $4(8 \%)$ \\
\hline (Central region) (40) & 40 & -—-—— & \multicolumn{3}{|c|}{ Not applicable } \\
\hline
\end{tabular}


tracing Brucella spp. transmission and identification of infection sources.

The study recommends that healthcare authorities determine the patient's geographic location, lifestyle, age, gender, occupational exposure, food consumption, other health conditions (antibiotic treatment) and family history. This information plus species-specific diagnosis is useful for improving the diagnostic capacity, reducing the diagnostic delay, introducing new treatment regimens and providing strategies to effectively cure even the most complex cases of brucellosis often seen in endemic areas.

\section{Consent statement}

Institutional ethical approval for the study was obtained from the Ethical Committee of King Abdulaziz University.

\section{Competing interests}

The authors declared that they have no competing interests.

\section{Authors' contributions}

IHK designed and performed the study experiments and was responsible for writing the manuscript. BAG participated in the laboratory experiments. SSM, TAK and KOA were responsible for data management, and revised the draft carefully for important intellectual content. All authors read and approved the final version of this manuscript.

\section{Acknowledgements}

This project was funded by the deanship of Scientific Research (DSR), King Abdulaziz University, Jeddah, under grant no. 03/079/429. The authors, therefore, acknowledge with thanks DSR technical and financial support.

\section{Author details}

'Biochemistry Department, Faculty of Science, King Abdulaziz University, Jeddah, Saudi Arabia. ${ }^{2}$ Biochemistry Department, Faculty of Science, Ain Shams University, Cairo, Egypt. ${ }^{3}$ Experimental Biochemistry Unit, King Fahd Medical Research Center (KFMRC), King Abdulaziz University, Jeddah, Saudi Arabia.

Received: 8 October 2012 Accepted: 15 March 2013

Published: 21 March 2013

\section{References}

1. Archibald LK, Reller LB: Clinical microbiology in developing countries. Emerg Infect Dis 2001, 7:302-305.

2. Memish ZA: Brucellosis control in Saudi Arabia: prospects and challenges. J Chemother 2001, 13:11-17.

3. Refai M: Incidence and control of brucellosis in the Near East region. Vet Microbiol 2002, 90:81-110

4. Memish Z, Mah M, Khan MY, Almahmoud S, et al: Brucellosis: clinical and laboratory observations in 160 bacteremic patients. J Infect 2000, 4:59-63.

5. Alshaalan M, Memish Z, Almahmoud S, et al: Brucellosis in children: clinical observations in 115 children. Int J Infect Dis 2002, 6:182-186.

6. Almuneef M, Memish Z, Alshaalan M, Albanyan E, Alaloola S, Balkhy H: Brucella melitensis bacteremia in children: Review of 62 cases. J Chemother 2003, 15:76-80.

7. Kiel F, Khan MY: Analysis of 506 consecutive positive serologic tests for brucellosis in Saudi Arabia. J Clinical Microbiol 1987, 25:1384-1387.

8. Khan MY: Brucellosis: observations on 100 patients. Ann Saudi Med 1986, 6:19-23.

9. Aleissa Y: Brucellosis in Saudi Arabia; past, present and future. Ann Saudi Med 1999, 19:403-405.

10. Hafez SM: The impact of uncontrolled animal importation and marketing on the prevalence of brucellosis in Saudi Arabia. Ann Saudi Med 1986, 6(Suppl):15-18.
11. Elberg SS: A guide for the diagnosis, treatment and prevention of human brucellosis, WHO UPH/81/31. Rev. 1. Geneva: World Health Organization; 1981.

12. Memish Z, Mah M: Brucellosis in laboratory workers at a Saudi Arabian Hospital. Am J Infect Control 2001, 29:48-52.

13. Al-Balla SR, Al-Aska A, Kambal A, Al-Hedaithy MA: Seasonal variation of culture positive brucellosis at a major teaching hospital. Ann Saudi Med 1994, 14(Suppl1):12-15.

14. Godfroid J, Cloeckaert A, Liautard JP, Kohler S, Fretin D, Walravens K, et al: From the discovery of the Malta fever's agent to the discovery of a marine mammal reservoir, brucellosis has continuously been a reemerging zoonosis. Vet Res 2005, 36:313-326.

15. Queipo-Ortuno MI, Morata P, Ocon P, Manchado P, Colmenero JD: Rapid diagnosis of human brucellosis by peripheral-blood PCR assay. J Clin Microbiol 1997, 35:2927-2930.

16. Redkar R, Rose S, Bricker B, DelVecchio V: Real-time detection of Brucella abortus, Brucella melitensis, and Brucella suis. Mol Cell Probes 2001, 15:43-52.

17. Chryssanthou E, Andersson B, Petrini B, Löfdahl S, Tollemar J: Detection of Candida albicans DNA in serum by polymerase chain reaction. Scand J Infect Dis 1994, 26:479-485.

18. Baily GG, Kranhn JB, Drasar BS, Stoker NG: Detection of Brucella melitensis and Brucella abortus by DNA amplification. J Trop Med Hyg 1992, 95:271-275.

19. Mayfield JE, Bricker BJ, Godfrey H, Crosby RM, Knight DJ, Halling SM, Balinsky $D$, Tabatabai LB: The cloning and nucleotide sequence of a gene coding for an immunogenic Brucella abortus protein. Gene 1988, 63:1-9.

20. Bricker BJ, Halling SM: Differentiation of Brucella abortus bv 1, 2, and 4, Brucella melitensis, Brucella ovis, and Brucella suis bv 1 by PCR. J Clin Microbiol 1994, 32:2660-2666.

21. Memish ZA, Almuneef $M$, et al: Comparison of the Brucella Standard Agglutination Test with the ELISA IgG and IgM in patients with Brucella bacteremia. Diagn Microbiol Infect Dis 2002, 44(Suppl 2):129-132.

22. Corbel MJ: Brucellosis: an overview. Emerg Infect Dis 1997, 3:213-221.

23. Yagupsky P: Detection of Brucellae in blood cultures. J Clin Microbiol 1999, 37:3437-3442.

24. Alton GG, Jones LM, Pietz DE: Laboratory techniques in brucellosis (2nd ed., Series No. 55). Geneva: World Health Organization; 1975:1-163.

25. Al Dahouk S, Tomaso H, Nöckler K, Neubauer H, Frangoulidis D: Laboratorybased diagnosis of brucellosis - a review of the literature: Part I. Techniques for direct detection and identification of Brucella spp. Clin Lab 2003, 49:487-505.

26. Al Dahouk S, Tomaso H, Nöckler K, Neubauer H, Frangoulidis D: Laboratorybased diagnosis of brucellosis - a review of the literature: Part II. Serological tests for brucellosis. Clin Lab 2003, 49:577-589.

27. Elfaki MG, Uz-Zaman $T$, et al: Detection of Brucella DNA in sera from patients with brucellosis by polymerase chain reaction. Diagn Microbiol Infect Dis 2005, 53(Suppl 1):1-7.

28. Al-Ajlan HH, Ibrahim AS, et al: Comparison of different PCR methods for detection of Brucella spp. in human blood samples. Pol J Microbiol 2011, 60(Suppl 1):27-33.

29. Radwan Al, Asmar JA, et al: Incidence of brucellosis in domestic livestock in Saudi Arabia. Trop Anim Health Prod 1983, 15:139-143.

30. Bilal NE, Jamjoom GA, et al: Brucellosis in the Asir region of Saudi Arabia. Saudi Med J 1991, 12:37-41.

31. Dean AS, Crump L, et al: Clinical Manifestations of Human Brucellosis: a Systematic Review and Meta-Analysis. PLoS Negl Trop Dis 2012, 6(12):e1929.

32. Kunda J, Fitzpatrick J, et al: Healthseeking behaviour of human brucellosis cases in rural Tanzania. BMC Publ Health 2007, 7. doi:10.1186/1471-2458-7-315.

doi:10.1186/1471-2334-13-145

Cite this article as: Kamal et al.: Two-stage PCR assay for detection of human brucellosis in endemic areas. BMC Infectious Diseases 2013 13:145. 